\section{pessoas partidas:}

\section{o comércio de partes de escravos (Piracicaba, Província de São Paulo, 1861-1887)}

Parts of People: The Trade in Parts of Slaves

(Piracicaba, Province of São Paulo, 1861-1887)
José Flávio

\section{MOTTA'}

\section{(1) jflaviom@usp.br \\ Luciana Suarez \\ GALVÃO'}

\section{(D) Isgalvao@usp.br}

\author{
Universidade \\ de São Paulo \\ São Paulo, SP, Brasil
}

\section{RESUMO}

Estudamos pequenos negócios de venda de partes ideais de escravos registrados em Piracicaba, província de São Paulo, no período de 1861 a 1887, durante o qual a localidade teve sua economia marcada pela cafeicultura. Foram 17 transações envolvendo 9 homens, 6 mulheres e duas crianças de poucos meses de idade. Percebemos que esse tipo de negócio esteve frequentemente vinculado ao resultado de partilhas em processos de inventários. O recebimento como herança da propriedade parcial de escravos acarretava essas pequenas operações de compra e venda entre herdeiros, produzindo amiúde como resultado a posse "na íntegra" das pessoas herdadas pelos compradores das partes em questão. Dessa forma, transacionar "um pedaço" de uma pessoa, o mais das vezes, equivalia a tão-somente ajustar a matemática cega da divisão equânime de um patrimônio entre aqueles que o herdavam.

\begin{abstract}
We studied small sales of ideal parts of slaves registered in Piracicaba, province of São Paulo, from 1861 to 1887, when the locality had its economy marked by coffee cultivation. There were 17 transactions involving nine men, six women and two infants. We noticed that this type of transaction was often linked to the result of partition of property in inventory processes. The inheritance of partial ownership of slaves entailed that sort of small buying and selling operations among heirs, often resulting in the possession "in full" of the persons inherited by the buyers of the slave parts. Thus, transacting "a piece" of a person, frequently, simply meant to adjust the blind math of the equitable division of an estate among those who inherited it.
\end{abstract}

Keywords: Internal slave trade, Expansion of coffee cultivation in São Paulo, Piracicaba, Economy of slavery.

Palavras-chave: Comércio interno de escravos, Expansão cafeeira paulista, Piracicaba, Economia da escravidão. 
D edicamos este artigo ao estudo de uma forma específica de transações envolvendo escravos, cuja finalidade era a compra e venda de partes ideais (metade, um terço, três oitavos etc.) das pessoas transacionadas. Além disso, nosso interesse está centrado nos pequenos negócios, nos quais se comercializaram partes ideais de um ou no máximo de dois cativos. Escolhemos para nossa análise, no que respeita ao espaço contemplado, o município de Piracicaba, localizado no chamado "Oeste histórico" da província de São Paulo. Elevada à categoria de cidade em 1856, Piracicaba, nos meados do Oitocentos, tinha o nome de Constituição, denominação alterada apenas na segunda metade da década de 1870.1

Nosso recorte temporal corresponde às últimas décadas de vigência da escravidão no Império do Brasil. A definição desse recorte vinculou-se, por um lado, à disponibilidade da principal fonte documental que utilizamos: as escrituras registradas no $2^{\circ}$ Cartório de Notas da localidade. Até 1887 esses documentos notariais referentes ao comércio da mercadoria humana ainda se faziam presentes, em que pese a cada vez maior proximidade da abolição da escravatura aos 13 de maio de 1888. Quanto à outra ponta do intervalo de tempo por nós privilegiado, notamos que tais registros se tornaram significativamente mais frequentes a partir do início da década de 1860, ao que tudo indica em obediência ao Decreto no. 2.699, de 28 de novembro de 1860, que em um de seus artigos dispunha o seguinte:

\begin{abstract}
Art. $3^{\circ} \mathrm{A}$ escritura pública é da substância de todo e qualquer contrato de compra e venda, troca e dação in solutum de escravos, cujo valor ou preço exceder de $200 \$ 000$, qualquer que for o lugar em que tais contratos se celebrarem ou efetuarem.

$\S 1^{\circ}$ As escrituras serão lavradas por ordem cronológica em livro especial de notas, aberto, numerado, rubricado e encerrado na forma da Legislação em vigor, por Tabelião de notas legitimamente constituído (...), e conterão (...) os nomes e moradas dos contraentes, o nome, sexo, cor, ofício, ou profissão, estado, idade e naturalidade do escravo e quaisquer outras qualidades ou sinais que o possam distinguir. (Coleção de Leis do Império do Brasil) ${ }^{2}$
\end{abstract}

Nesses 27 anos de 1861 a 1887 a província de São Paulo foi marcada pela expansão da cafeicultura, trilhando uma trajetória, iniciada ainda no período colonial em especial na região do Vale do Paraíba da capitania paulista, e que avançou no decurso do Império em direção ao oeste provincial. Essa expansão, à qual por exemplo Monteiro Lobato referiu-se como "onda verde" (Cf. LOBATO, 2009), deu-se, adicionalmente, em paralelo ao evolver da assim chamada "questão servil”, passível de ser acompanhada mediante a observação da legislação dedicada aos escravos, com destaque, no II Reinado, para a lei de extinção do tráfico negreiro, de 1850, a lei de libertação dos nascituros, de 1871, a lei dos sexagenários, de 1885, e a já mencionada Lei Áurea, de 1888 , declarando extinta a escravidão no Brasil.

Piracicaba foi uma das localidades arrebatada pelo ímpeto da onda verde. Essa afirmativa é corroborada quando comparamos os comentários realizados acerca da 
localidade por Augusto Emílio Zaluar, em viagem por ele iniciada em fins de 1859, com os Apontamentos de Manuel Eufrásio de Azevedo Marques, originalmente publicados em 1879. O primeiro escreveu:

A sua produção de café e açúcar regula, termo médio, em cento e cinquenta mil arrobas. É preciso notar que a cultura do café é aqui de data muito recente, pois ainda há muito pouco tempo os Piracicabanos se entregavam exclusivamente ao cultivo da cana, que com esta inovação tem consideravelmente diminuído. (ZALUAR, 1975, p. 151, grifo nosso)

Já o comentário de Azevedo Marques sobre Piracicaba foi o seguinte:

A sua única indústria é a lavoura, sobressaindo a do café e a da cana, de que conta muitas e importantes fazendas. (...) A exportação do município regula, termo médio, 130.000 arrobas de café, 50.000 de açúcar e 20.000 de algodão. (MARQUES, 1953 , v. 1, p. 198)

Para 1886, ano bastante próximo do limite superior do período de que tratamos, Sergio Milliet (1939, p. 43) indicou uma produção cafeeira de 300.000 arrobas em Piracicaba.

O banco de dados no qual nos baseamos para a elaboração deste texto traz os informes constantes de sete livros localizados no $2^{\circ}$. Cartório de Notas daquele município, todos eles específicos para o lançamento de escrituras referentes a negócios envolvendo escravos. ${ }^{3}$ No total do período $1861-1887$ foram 17 os casos atinentes a compras e vendas de partes ideais de um ou no máximo de dois cativos. ${ }^{4}$

Na próxima seção explicitamos o contexto historiográfico no qual se origina e se insere nossa preocupação em analisar as transações envolvendo partes de escravos. Em seguida, dedicamos nossa atenção precipuamente às ditas compras e vendas. Num primeiro momento, procuramos dimensionar tais negócios no fluxo de transações envolvendo cativos no município analisado; nesse esforço de dimensionamento, trazemos também informes acerca da relevância dessas "pessoas partidas" enquanto item a compor o estoque de escravos arrolado no patrimônio de escravistas. Isto é feito com base em processos de inventários post-mortem atinentes à localidade também paulista de Ribeirão Preto em período ligeiramente mais alongado do que o coberto pelas escrituras de Piracicaba. Num segundo momento, caracterizamos, uma a uma, essas pequenas operações de compra e venda de partes ideais de cativos. Nossos achados são sumariados na seção de considerações finais.

\section{Momentos críticos no cotidiano dos escravos: inventários e partilhas; negócios de compra e venda}

Nunca será demais enfatizar que a violência era um componente a marcar de forma inerente as relações entre senhores e escravos numa sociedade escravista como a do Brasil colonial e imperial. Nesse contexto, não nos deve surpreender serem 
muitos os estudiosos a apontar, como ilustrações por excelência dessa violência, o potencial possuído por algumas situações específicas passíveis de serem vivenciadas no cotidiano dos escravos. Uma dessas situações era a morte de proprietários de cativos e a eventual partilha do patrimônio por eles acumulado durante suas vidas, aí incluídas as pessoas escravizadas. Outra dessas situações era a destinação de escravos para transações diversas, a exemplo das de compra e venda. Desnecessário salientar, tendo em vista as relações de poder e dominação entre os envolvidos, como poderiam ser nefastas tais situações para os cativos, capazes de desorganizar completamente suas existências, causando o rompimento e a destruição de relacionamentos tais como os de família, construídos o mais das vezes a duras penas e durante longos períodos. De fato, confrontavam-se, naqueles momentos, de um lado, indivíduos que haviam acumulado os bens inventariados, vendiam e compravam pessoas; e, de outro, indivíduos que integravam o arrolamento dos bens a serem partilhados, eram vendidos e comprados.

Evidentemente, nem todas as partilhas em processos de inventários post-mortem, assim como nem todas as transações de compra e venda implicavam necessariamente esses resultados dolorosos. Não foi incomum a preservação, ao menos em alguma medida, dos relacionamentos construídos entre os escravos. No caso das partilhas, é notável, por exemplo, o caso dos inventários de Paraíba do Sul, na província do Rio de Janeiro, trabalhados por João Fragoso e Manolo Florentino:

José Agostinho Castelo Branco, plantador e traficante de negros, era possuidor, em 1839, de 112 escravos em Paraíba do Sul e de 26 em Luanda. De seus cativos no Brasil, 24,1\% estavam organizados em famílias. Sua mulher, a inventariante, solicitou ao juiz de órfãos da comarca que não permitisse a separação dos escravos na hora da partilha da herança, "pois seria manifesta injustiça dividirem-se pais para uma parte e mães e filhos para outra". Exemplo também importante nos é dado pelo inventário do Comendador Ignácio Pereira Nunes, de 1857. Dos 418 escravos que deveriam ser repartidos entre 14 herdeiros, 100 $(23,9 \%)$ se encontravam organizados em 37 famílias. Destas, 21 $(63,6 \%)$ foram preservadas e reuniam 56 indivíduos, 4 famílias foram certamente desmembradas e conformavam 11 pessoas, não havendo informações sobre o destino das 13 famílias restantes. Por fim, temos o caso do inventário de Porcina de Paula Dias (1873), cujos 102 escravos deveriam ser divididos entre 7 herdeiros. Existiam 15 famílias somando 46 pessoas ( $45,1 \%$ do plantel), das quais $10(66,7 \%)$ foram preservadas, reunindo 30 $(65,2 \%)$ indivíduos. Apenas duas famílias foram desmembradas. Observe-se que tanto no caso de Pereira Nunes como no de Paula Dias consideramos como famílias desmembradas aquelas que perderam pelo menos um dos seus membros, o que não significa que a família necessariamente tenha sido esfacelada. (FRAGOSO; FLORENTINO, 1987, p. 166)

É bem possível que a elevada frequência de manutenção dos relacionamentos familiares encontrada em Paraíba do Sul seja atípica. Os próprios autores citados 
fazem questão de frisar que esse resultado “(...) não significa, no entanto, que tal fato constituísse a regra geral do mercado e da partilha de heranças”. Nessa medida, deixam claro que "a intenção aqui é de apenas alertar para a importância da preservação das familias” (FRAGOSO; FLORENTINO, 1987, p. 166).

De maneira similar, essa preservação das famílias leva os autores a sugerir, em Paraíba do Sul, a existência de um "mercado de famílias escravas", com o que se tornaria algo nuançado também o impacto negativo das compras e vendas da mercadoria humana. Uma vez mais, no entanto, seria possível pensar os negócios envolvendo famílias de cativos como atípico. É o que se depreende da leitura de Robert Conrad (1985, p. 191): “(...) a vítima do tráfico interno brasileiro, como o africano antes dele, era normalmente vendida sozinha (...). Familias brasileiras inteiras às vezes migravam para uma nova localidade. Mas esta era a exceção".

Em suma, tal como nas partilhas, outra situação potencialmente terrível na vida dos escravos, a sua negociação, sua compra e venda, nem sempre tinha esse potencial tornado realidade. Essa dupla possibilidade é apontada, por exemplo, em estudo sobre as localidades paulistas de Guaratinguetá e Silveiras, por José Flávio Motta e Renato Marcondes:

(...) encontramos também indícios tanto de ruptura como de preservação da família cativa. Tais indícios encontraram-se, de um lado, nos casos de vendas de indivíduos isolados que eram descritos como casados e, de outro, nos escravos transacionados "em família" (casais, com ou sem prole, e solteiros e viúvos com filhos), estes últimos correspondendo a pouco menos de um quinto do total. (MOTTA; MARCONDES, 2000, p. 297)

Em que pese a complexa realidade decerto subjacente à dupla possibilidade mencionada, o que nos interessa particularmente neste artigo são os casos que poderiam eventualmente ser caracterizados como compondo uma terceira alternativa. Nesta, o impacto negativo das partilhas, claramente evidenciado nos inventários, viu-se negado na realidade e, amiúde, as próprias transações de compra e venda, realizadas após e mesmo em decorrência das ditas partilhas, contribuíram para reverter aquele impacto negativo aparente.

Uma corroboração da existência dessas reversões é o estudo de José Flávio Motta e Agnaldo Valentin sobre a numerosa escravaria de D. Anna de Oliveira Roza (MOTTA; VALENTIN, 2002). Moradora na localidade paulista de Apiaí, D. Anna, já viúva e com pouco mais de 65 anos, faleceu em fins de 1818 ou inícios de 1819. Em seu inventário foram arrolados, entre outros bens, quase uma centena de cativos. Era uma escravaria composta por mais de vinte famílias, muitas crianças (40,1\% dos cativos com menos de 15 anos de idade). E eram também muitos os herdeiros: 19. Dessa forma, não foi possível fazer a repartição dos bens entre tantos beneficiários e, ao mesmo tempo, cuidar da preservação daquelas famílias escravas. Cada herdeiro recebeu exatamente cinco cativos e muitos dos grupamentos familiares foram esfacelados. Porém, os autores utilizaram como fontes não apenas o inventário e testamento de D. 
Anna (e inventários de alguns de seus irmãos), mas também as listas nominativas dos habitantes de Apiaí referentes a vários anos, em especial 1817 e 1824 (antes e depois do falecimento da escravista). Ao cruzar tais fontes, perceberam que houve rupturas de relacionamentos na partilha desfeitas posteriormente (se é que em algum momento haviam mesmo ocorrido) e as pessoas envolvidas novamente apareciam juntas em recenseamentos posteriores ao inventário. Nas palavras dos autores, nas partilhas

(...) é plausível supor que, muitas vezes, estejamos nos defrontando com repartições "ideais". Este parece ser o caso do inventário de D. Anna, e a existência de uma multiplicidade de casos semelhantes não seria, cremos nós, nada surpreendente. Isto não significa, deixemos de imediato bem claro, que todas as destruições de famílias escravas sugeridas em um processo de inventário devam ser, a priori, negadas sob o argumento de que são rupturas apenas aparentes; mas algumas realmente podem sê-lo." (MOTTA; VALENTIN, 2002, p. 182)

Tendo em vista esse caminho acima brevemente descrito trilhado pela historiografia, nosso objetivo neste artigo é entender as características de um tipo específico de transação de compra e venda de escravos, no qual esse traço de uma negociação "aparente", ou "fictícia" é algo evidente. De fato, as transações de partes ideais de pessoas, ainda que de inegável concretude jurídica e econômica, significavam, em verdade, ajustes feitos pelos envolvidos, mormente tornados necessários exatamente pela ocorrência prévia de um processo de partilha de bens inventariados. Assim como nenhum herdeiro levaria "meio" escravo para sua casa, e nenhum vendedor nas escrituras por nós analisadas se desfaria de "metade" de um cativo, as duas situações, tomadas conjuntamente, seriam eficientes para "resolver" a impossibilidade da partição de pessoas. ${ }^{5}$

\section{Pequenos negócios de compra e venda de partes de escravos}

\section{Sobre a dimensão desses pequenos negócios}

No Quadro 1 apresentamos algumas primeiras informações extraídas das escrituras analisadas neste artigo. Listamos os nomes das pessoas negociadas, suas idades e as datas de efetivação dos respectivos registros. Foram nove homens e seis mulheres. Duas dessas escravas foram vendidas juntamente com suas filhas, nos dois casos bebês com menos de um ano de idade. Uma dessas mães acompanhadas de suas crianças foi objeto de duas transações. Outra das mulheres, esta desacompanhada, foi igualmente objeto de duas operações de compra e venda de partes ideais. Vale dizer, um conjunto de 17 pessoas e um total de 17 transações.

Considerado o intervalo de 1861 a 1887, computamos em Piracicaba os registros de 603 negócios envolvendo um total de 1.692 cativos. Dessa forma, percebemos que as compras e vendas de partes ideais de pessoas escravizadas corresponderam a cerca de $3 \%$ dos negócios envolvendo a mercadoria humana. No tocante à quantidade de indivíduos, as transações objeto de nossa atenção abarcaram algo como um centésimo 
Quadro 1 - Escravos negociados em parte. Piracicaba, 1861-1887

\begin{tabular}{lcc}
\hline Nome & Idade (em anos) & Data do registro \\
\hline Francisco & 25 & $23 / 07 / 1862$ \\
Tobias & 28 & $24 / 08 / 1865$ \\
Celestina \& Virgínia & $30 /$ zero & $22 / 11 / 1865$ \\
Benedita \& Mafalda & $13(16)^{\mathrm{a} / \text { zero }}$ & $13 / 06 / 1867 ; 05 / 02 / 1868$ \\
Domingos & 27 & $13 / 04 / 1868$ \\
Benedito & 15 & $01 / 10 / 1868$ \\
Silvério & 30 & $15 / 02 / 1870$ \\
Benedito & 14 & $03 / 08 / 1871$ \\
Francisco & 14 & $14 / 12 / 1871$ \\
Adão & 35 & $02 / 01 / 1874$ \\
Catharina & 28 & $01 / 04 / 1874 ; 22 / 06 / 1874$ \\
Anacleta & 15 & $30 / 07 / 1875$ \\
Adão & 32 & $02 / 07 / 1877$ \\
Eva & 48 & $15 / 03 / 1881$ \\
Honória & 28 & $12 / 10 / 1885$ \\
\hline
\end{tabular}

aBenedita foi descrita com 13 anos no documento de 13 de junho de 1867, e com 16 no de 05 de fevereiro de 1868.

Fonte: Escrituras de transações envolvendo escravos ( $2^{\circ}$ Cartório de Notas de Piracicaba).

do total de cativos componentes do fluxo do comércio de pessoas de nosso banco de dados sobre Piracicaba.

Para formarmos uma ideia mais apurada sobre a expressividade dessas cifras, convém fornecermos um referencial comparativo acerca da relevância da propriedade segmentada da mercadoria humana nos "estoques" da propriedade escrava. Em outras palavras, há que averiguar se existia correspondência entre o fluxo e o estoque de partes ideais de cativos. Se nossa fonte principal, as escrituras de compra e venda, informam sobre o fluxo de escravos, tomemos para construir esse referencial de comparação uma fonte alternativa, que nos apresenta dados sobre o estoque de cativos. São os processos de inventários post-mortem. Valemo-nos de informes colhidos acerca de outra localidade do "Oeste histórico" paulista, situada mais a oeste do que Piracicaba, qual seja, Ribeirão Preto, e referentes a um período, 1849 a 1888 , um pouco mais alongado do que o das nossas escrituras.

A comparação pertinente é a seguinte: em uma amostra de 217 inventários, havia $15(6,9 \%)$ processos nos quais partes de escravos integravam o patrimônio inventariado. ${ }^{6} \mathrm{E}$ do total de 824 cativos arrolados naqueles 217 inventários, eram 24 os descritos como possuídos em partes ideais (2,9\%). Como esperado, tanto no fluxo como no estoque, a posse parcial de pessoas correspondia a uma pequena parcela 
do conjunto da escravaria. Contudo, os maiores porcentuais foram os calculados nos inventários. Várias podem ser as causas dessa diferença. Talvez os inventariados, não fosse seu falecimento, teriam ou vendido aquelas partes ideais de cativos que possuíam, ou comprado o restante daqueles indivíduos de modo a obter sua posse

integral. É também possível que não tivessem meios de realizar esses ajustes em sua propriedade; ou, mesmo, não tivessem vontade de fazê-lo. Neste último caso, os porcentuais superiores nos inventários indiciariam que a mera propriedade da mercadoria humana poderia eventualmente gerar um interesse que ia além do efetivo usufruto (ou pelo menos do pleno usufruto) da mão de obra compulsória.

Em outras palavras, se dois diferentes proprietários detivessem, cada um, metade de um escravo, um deles poderia decidir-se a comprar a parte possuída pelo outro (gerando o fluxo expresso na escritura de compra e venda), ou algum esquema de utilização compartilhada do cativo deveria ser ajustado entre seus dois senhores, mantendo-se a propriedade fracionária como item a compor o patrimônio de ambos. Ainda que provenientes de diferentes localidades (e, claro, extraídas de fontes documentais de natureza diversa), as cifras de Piracicaba e Ribeirão Preto talvez indiquem que a primeira dessas alternativas era menos frequente do que a segunda.

\section{Descrição dos pequenos negócios de compra e venda de partes de escravos}

\section{Francisco}

O primeiro negócio envolvendo parte de um escravo com que nos defrontamos nos livros notariais compulsados foi o descrito em escritura datada aos 23 de julho de 1862. Cândido de Souza Palma vendeu uma parte de aproximadamente um terço do escravo Francisco para Antonio José de Souza. O documento não informa o local de moradia do vendedor, mas o comprador residia em Capivari, localidade bastante próxima a Piracicaba. O trecho a seguir, transcrito da escritura, apresenta informações adicionais sobre o cativo e sobre a transação:

(...) foi dito pelo primeiro contratante que vendia ao segundo uma parte de cento e trinta mil réis que possui em um escravo de nome Francisco crioulo de vinte e cinco anos preto e casado avaliado no inventário do finado Antonio Pedro de Souza por quatrocentos e cinquenta mil réis, pela quantia de trezentos mil réis que os recebeu parte à vista e o restante em uma obrigação. (Constituição-1) ${ }^{7}$

Uma característica recorrente nas transações de partes ideais de cativos é sua ocorrência em momento posterior à efetivação dos trâmites de um processo de inventário e à definição da respectiva partilha entre os herdeiros dos bens arrolados de propriedade do inventariado. Assim, foi por conta do inventário de Antonio Pedro de Souza que parte de Francisco chegou às mãos de Cândido de Souza Palma. Percebemos, ademais, haver diferença substancial entre a avaliação no inventário (Rs. $130 \$ 000)$ e o preço de venda da parte negociada do jovem escravo (Rs. 300\$000). 
O comprador, que não pagou à vista a totalidade do preço ajustado, arcou também com o imposto de meia sisa, cobrado a uma taxa ad valorem naquele início da década de 1860: Rs. $6 \$ 000$, correspondentes a $2 \%$ do valor do negócio. ${ }^{8} \mathrm{O}$ tabelião não fez constar da escritura menção alguma aos outros cerca de dois terços de Francisco. No entanto, a presença do sobrenome "Souza" em ambos os contratantes e também no proprietário anterior cuja morte acarretou o inventário referido, torna plausível sugerirmos a possibilidade de Antonio José, antes ainda da transação registrada em julho de 1862, já ser coproprietário do crioulo Francisco. Outrossim, o documento silencia completamente acerca da identidade e localização do cônjuge do cativo.

\section{Tobias}

Outra venda de parte de escravo foi registrada em 24 de agosto de 1865. Antonio de Camargo Penteado vendeu para José de Campos Pacheco parte de Tobias, cabra de 28 anos de idade, casado e do serviço da roça, parte essa que recebeu por herança de sua finada mãe. O preço ajustado foi de Rs. $540 \$ 000$ e Pacheco recolheu a meia sisa de Rs. $15 \$ 000$. Esse imposto, de meados da década de 1860 a meados dos anos de 1870, passou a ser cobrado pelo valor específico de trinta mil-réis, fornecendo-nos o indício de que a transação se referiu possivelmente a metade do escravo. Os dois contratantes residiam na província paulista, em Pirapora, e ambos foram representados por terceiros: assinaram o documento um procurador do comprador e o curador do vendedor. A representação do vendedor deveu-se ao fato de Penteado ser interdito. A leitura do fragmento seguinte, correspondente à autorização judicial transcrita pelo tabelião na escritura da venda é esclarecedora acerca de características adicionais do negócio:

Pelo presente alvará de autorização autorizo a José de Barros Gurgel, curador do desassisado Antonio de Camargo Penteado, a outorgar a José de Campos Pacheco a competente escritura de venda do direito que tem o seu curatelado por herança materna no escravo Tobias de que é condômino o mesmo José de Campos Pacheco, pela quantia de quinhentos mil réis, digo quinhentos e quarenta mil réis, visto ter o proposto comprador oferecido a maioria de quarenta mil réis sobre a de quinhentos, valor atribuído ao mesmo desassisado sobre aquele escravo na avaliação total de um conto e oitocentos mil réis que teve o mesmo escravo no respectivo inventário, ficando a cargo do comprador todas as despesas da licença, sisa e escritura, pelo que deverá o comprador, digo o curador logo que realizar a venda entrar para o cofre com a quantia integral de quinhentos e quarenta mil réis. (Constituição-2)

Quando comparado ao caso anterior, vemos aqui repetir-se a forma de aquisição prévia da parte negociada do cativo: Tobias, em 1865, tal como Francisco, em 1862, havia sido herdado. Também nada ficamos sabendo sobre o cônjuge de Tobias. Além disso, o que apenas pudemos sugerir na venda da terça parte de Francisco, agora é explicitado na negociação da metade de Tobias: o comprador já dividia a propriedade deste roceiro antes da transação por nós descrita. Mas há uma diferença interessante. 
Ainda que o tabelião informe que o comprador acresceu Rs. $40 \$ 000$ à soma correspondente à avaliação da parte de Tobias atribuída a Antonio no inventário de sua mãe (Rs. 500\$000), a avaliação do total do cativo (Rs. 1:800\$000) implicaria ser aquela parte inferior a um terço. Haveria, portanto, uma inconsistência com o valor cobrado da meia sisa naquela transação. Teria esse imposto sido recolhido em montante além do devido? Ou seria a falta de juízo do vendedor motivo suficiente para a definição de um preço subestimado a ser pago ao desajuizado? Se não nos é possível responder a essas questões, sabemos, de outra parte, que o valor da avaliação de Tobias pouco se afastou do preço nominal médio calculado na venda de 49 homens com idades de 15 a 29 anos no período 1861-1869 em Piracicaba, que foi de Rs. 1:819\$388 (Cf. MOTTA, 2012a, p. 148).

No que respeita ao curador, que deveria defender os interesses do desassisado, ele era José de Barros Gurgel e à época residia em Piracicaba. No Almanak de 1873, ele apareceu como solicitador no Termo de Jaú, e também como suplente de vereador e de subdelegado no município do mesmo nome, ainda freguesia em 1865 e alçado a vila em 1866, situado a poucas dezenas de quilômetros de Piracicaba (Cf. LUNÉ; FONSECA, 1985, p. 547). Por seu turno, o procurador do comprador, Dr. Francisco da Costa Carvalho, bacharel, foi listado no mencionado Almanak entre os advogados dos Municípios de Piracicaba e de Limeira (Cf. LUNÉ; FONSECA, 1985, p. 464 e 520).

\section{Celestina e Virgínia}

Em 22 de novembro de 1865 foram negociadas Celestina, crioula, solteira, negra de 30 anos de idade, cozinheira, e sua filha, Virgínia, de 4 meses. Mariano José de Oliveira, morador em Piracicaba, vendeu, por Rs. 240\$000, parte da escrava e "parte correspondente de sua filha", ambas obtidas previamente por herança de sua sogra. 0 comprador, Francisco Coelho Barbosa, também residente em Piracicaba, recolheu de meia sisa Rs. $10 \$ 000$. Tem esse nome um dos três carpinteiros arrolados no município pelo Almanak de 1873 (Cf. LUNÉ; FONSECA, 1985, p. 465). Se esta última quantia correspondia então, como vimos, a um terço da meia sisa devida na venda de um escravo, a escritura não trouxe a informação acerca da proporção transacionada de Celestina. Contudo, o tabelião informou o valor pelo qual ela havia sido avaliada no inventário da sogra de Mariano: Rs. 1:800\$000. Assim, além da inconsistência verificada entre esses montantes, aparentemente não se recolheu imposto sobre Virgínia. Haveria aí algum indício das expectativas dos contratantes sobre as possibilidades de sobrevivência da pequena cativa?

Se de fato não se cobrou a meia sisa sobre a venda de parte de Virgínia, nada indica que o valor da escritura, Rs. $240 \$ 000$, representasse mais do que meramente a parte vendida de Celestina. Em Motta (2012a, p. 148) foram colhidos os informes do preço nominal médio de 65 mulheres transacionadas em Piracicaba no período 18611869, igual a Rs. 1:275\$954. Desse conjunto, 35 escravas tinham de 15 a 29 anos de idade, tendo seu preço médio nominal atingido Rs. 1:513\$171. Em suma, se a venda em questão foi realmente de um terço da cozinheira, o preço ajustado pareceu-nos subestimado. 


\section{Benedita e Mafalda}

Analisaremos as duas próximas transações em conjunto, pois referem-se às mesmas escravas e um mesmo comprador, Dr. Felipe Xavier da Rocha. Ele havia sido suplente de Deputado Geral pelo $8^{\circ}$ Distrito (Rio Claro) na $10^{\mathrm{a}}$ Legislatura (1857-1860). Em 1873, o bacharel Felipe era um dos capitalistas e também um dos proprietários em Piracicaba (Cf. LUNÉ; FONSECA, 1985, p. 146 e 463-464). No primeiro dos negócios em tela, o vendedor era Jerônymo José Lopes de Siqueira, residente em São Carlos do Pinhal e mencionado, no Almanak de 1873, como escrivão da Delegacia de Polícia da Comarca da Constituição (Cf. LUNÉ; FONSECA, 1985, p. 461). No segundo, quem vendia era João Lopes Corrêa, morador em Piracicaba.

Destoando das demais situações analisadas até aqui, as duas escrituras de venda de partes de Benedita e Mafalda não trouxeram qualquer indicação sobre a forma prévia de aquisição de mãe e filha pelos respectivos vendedores. Todavia, Jerônymo e João compartilhavam o sobrenome Lopes, o que pode ser um indício de mais um caso de partilha de bens inventariados acarretando a divisão, ao menos ideal, de pessoas escravizadas que integravam o patrimônio que se dividia.

As ditas escrituras foram datadas em 13 de junho de 1867 e 5 de fevereiro de 1868 . De forma similar ao negócio envolvendo Celestina e Virgínia, novamente tratou-se da comercialização de uma mãe solteira e sua filha ainda bebê. Benedita, crioula natural de Piracicaba, de cor fula e serviços domésticos, foi descrita como tendo 13 anos no documento de 1867 e 16 no de 1868; Mafalda, mulata, tinha apenas 2 meses de vida por ocasião do primeiro registro.

As duas transações tiveram o mesmo valor, Rs. $600 \$ 000$, e em cada uma delas a meia sisa recolhida foi de Rs. 30\$000. Em que pesem as inconsistências apontadas nos casos anteriores, o montante de imposto cobrado nas compras que o Dr. Felipe realizou estaria conforme a negociação, tanto em junho de 1867 como em fevereiro de 1868 , de metade de duas cativas. Dessa forma, em um intervalo de pouco menos de oito meses, o bacharel teria adquirido a totalidade de mãe e filha e pago a meia sisa na forma exigida.

\section{Domingos}

Menos claro para nós foi o destino de Domingos, crioulo de 27 anos de idade, solteiro, preto e roceiro, motivo da escritura lançada aos 13 de abril de 1868. Sabemos que a transação se referiu apenas a parte ideal do escravo, mas não foi explicitado no documento que parte seria essa. O valor recolhido de meia sisa, Rs. $15 \$ 000$ forneceu-nos a sugestão de que a venda teria sido de metade de Domingos. Mas inconsistências surgiram uma vez mais. Por um lado, dito escravo, então vendido por Dona Gertrudes de Arruda Camargo, escreveu o tabelião, foi "avaliado no inventário de seu finado marido José Luis Álvares Gonzaga por um conto e oitocentos mil-réis”. Por outro, o preço ajustado na escritura foi de Rs. 576\$105. Tal como no caso de Tobias, a avaliação no inventário aproximou-se do preço nominal médio de cativos de 15 a 29 anos de idade ao longo dos anos de 1860 em Piracicaba, calculado em Motta (2012a, p. 148). 
A única Dona Gertrudes de Arruda Camargo por nós localizada no Almanak de 1873 foi inserida na lista de lavradores do município de Campinas; na escritura de 1868 ela foi descrita como moradora de Piracicaba. No que respeita ao comprador, Joaquim Caetano Gomes Carneiro, que na escritura é dito residente no Distrito da Freguesia d’Água-Choca, pudemos identificá-lo em 1873 como subdelegado no município de Monte-Mor (Cf. LUNÉ; FONSECA, 1985, p. 367). O texto que na aludida publicação introduziu os informes desse município dirimiu qualquer dúvida sobre a identidade do comprador, embora não saibamos se o restante do cativo negociado, quiçá outra metade, já era possuído pelo subdelegado:

\section{MUNICÍPIO DE MONTE MOR.}

A Vila de Monte Mor pertence ao Termo de Itu. Ereta Freguesia em 1832 com a denominação de Nossa Senhora do Patrocínio de Água Choca, em substituição da de Capivari de Cima por que era conhecido aquele lugar, foi elevada à categoria de Vila a 24 de Março de 1871, com o nome de Monte Mor.

A 7 de Janeiro do corrente ano deve prestar juramento e tomar posse a sua primeira câmara municipal. (LUNÉ; FONSECA, 1985, p. 366)

\section{Benedito}

No primeiro dia de outubro de 1868, Luiz Antonio de Almeida Barros e seu cunhado, Francisco de Paula Ferraz, cada um deles proprietário de uma parte do jovem Benedito, registraram a escritura de venda das ditas partes. Uma vez mais nos defrontamos com o desdobramento de uma partilha de bens. As partes ideais daquele crioulo, preto de 15 anos de idade e do serviço da roça, foram

(...) havidas em terça deixada pela finada Dona Isabel de Campos Penteado segundo consta do respectivo inventário procedido pelo Juízo de Órfãos desta Cidade, de onde também consta ter sido dito escravo avaliado por um conto e duzentos mil. (Constituição-2)

O tabelião acrescentou que cada vendedor possuía uma parte de Rs. $174 \$ 239$ e a escritura foi passada por Rs. 348\$478. O comprador, José Carlos Ferraz de Campos, recolheu de meia sisa a importância de doze mil-réis, isto é, dois quintos do imposto cheio então incidente sobre a venda de um escravo. Dessa forma, se supusermos que cada um dos vendedores negociou o equivalente a um quinto de Benedito, o preço pago por José Carlos teria sido menor do que o valor de avaliação do cativo no inventário de Dona Isabel.

Todos os contratantes envolvidos nessa transação estiveram presentes ao ato e assinaram a escritura. Foram, vendedores e comprador, descritos como moradores em Piracicaba. A busca no Almanak de 1873 permitiu-nos localizar Luiz Antonio de Almeida Barros entre os fazendeiros daquele município e Francisco de Paula Ferraz entre os fazendeiros de café do município de São João do Rio Claro, distante pouco 
mais de 30 quilômetros. Não identificamos nenhum José Carlos Ferraz de Campos. Não obstante, um funileiro no município de Santa Bárbara, no Termo da Constituição, chamava-se José Ferraz de Campos e talvez tenha sido ele o comprador dos dois quintos de Benedito (Cf. LUNÉ; FONSECA, 1985, p. 509 e 468). A existência de algum laço de parentesco entre ele e os vendedores não pode, é claro, ser descartada. ${ }^{9}$

\section{Silvério}

Em 15 de fevereiro de 1870, outro negócio realizado no âmbito local fez com que o tabelião se deslocasse até o sítio São José, no Termo de Constituição. A propriedade pertencia ao Tenente Coronel José Ferraz de Camargo, descrito como comprador. O outro contratante, Antonio Benedito Alves Lima, era genro do militar. A venda, ajustada em um conto de réis, era de parte do escravo Silvério, crioulo de 30 anos de idade, preto, solteiro e do serviço da roça. A escritura trouxe também a seguinte informação: "(...) no qual [escravo-JFM/LSL] tem outra igual parte o menor Francisco Ferraz de Camargo, filho do comprador".

Dessa forma, o roceiro negociado era possuído em partes iguais por dois filhos do Tenente Coronel Ferraz de Camargo: metade de Silvério era do menor Francisco e a outra metade da filha casada com Alves Lima. Ao adquirir este último "pedaço", o comprador recolheu meia sisa de Rs. $15 \$ 000$ e de certa forma unificou a propriedade do cativo, uma vez que Francisco ainda vivia sob o pátrio poder. No Almanak de 1873, localizamos o Tenente Coronel entre os proprietários arrolados no município de Piracicaba (Cf. LUNÉ; FONSECA, 1985, p. 464).

O preço ajustado entre as partes contratantes pareceu-nos favorável à ponta vendedora. É fato que, comparados aos preços praticados nos anos de 1860 , os do decênio subsequente, para "mercadorias" com as características de Silvério, haviam sofrido aumentos. Por exemplo, o preço nominal médio calculado com base em 93 cativos homens com 15 a 29 anos de idade transacionados em Piracicaba no período 1870-1880 foi de Rs. 2:053\$763; como mencionamos anteriormente, havia atingido a cifra de Rs. 1:819\$388 no período 1861-1869, calculado para 49 homens na mesma faixa etária (Cf. MOTTA, 2012a, p. 230 e 148).

Todavia, é preciso termos em mente que o movimento ascendente dos preços de escravos ganhou força em especial a partir de meados da década de 1870, com a intensificação do comércio interprovincial. Em verdade, houve mesmo baixa nos primeiros anos daquele decênio, eventualmente refletindo as indefinições sentidas no mercado em vista das discussões em torno da libertação dos nascituros. Assim, servindo-nos do mesmo estudo referido no parágrafo anterior e computando preços reais (ano-base 1861), uma vez mais de cativos homens de 15 a 29 anos de idade, temos os seguintes preços médios: $1861-1869$, Rs. 1:603\$834; $1870-1873$, Rs. 1:447\$586; 1874-1880, Rs. 1:687\$234 (Cf. MOTTA, 2012a, p. 231).

\section{Benedito}

A próxima transação a receber nossa atenção envolveu múltiplos vendedores. Eram Escolástica Xavier Leite e outras 5 pessoas, todos irmãos, alguns residentes na Freguesia de São Pedro, no Termo da Constituição, outros na Vila de Moji Mirim. 
Nem todos estavam presentes, sendo os ausentes representados pelo procurador Cornélio de Oliveira César. Este último, em 1873, era escrivão (interino) na Coletoria Geral e Provincial do município de Piracicaba (Cf. LUNÉ; FONSECA, 1985, p. 463). O comprador era Manoel Ernesto de Matos, residente em Piracicaba, que recolheu Rs. $22 \$ 500$ de meia sisa. Esse montante corresponde a 75\% do tributo "cheio" incidente na compra e venda de um escravo. Três quartos, ou seis oitavos do cativo.

Pelo relato do tabelião na escritura, sabemos que os seis irmãos haviam herdado as partes da pessoa que vendiam no processo de inventário de sua falecida mãe. E lemos também a informação de que havia ao menos um sétimo irmão, menor e igualmente herdeiro, porém que não participou do negócio. Benedito, o objeto da escritura registrada aos 03 de agosto de 1871, era bastante jovem (14 anos). Crioulo, mulato, solteiro, natural de Piracicaba, sem aptidão declarada, foi comprado por Rs. $1: 100 \$ 000$.

\section{Francisco}

Também 14 anos tinha Francisco, em 04 de dezembro de 1871, quando ao que tudo indica dois terços dele foram comercializados. O negócio envolveu três irmãos, dois dos quais venderam ao terceiro as partes ideais que possuíam naquele escravo, sendo que o irmão comprador era igualmente proprietário de parte do rapaz previamente à efetivação da transação em tela, acertada pelo valor de Rs. $535 \$ 735$. A propriedade dividida entre irmãos aponta para a ocorrência de um processo prévio de partilha de bens, motivo gerador, é oportuno repisarmos, se não de todos, ao menos da grande maioria desses pequenos negócios envolvendo partes ideais de escravos que vimos analisando.

Francisco era crioulo, preto e solteiro e não foi declarada nenhuma aptidão específica que ele detivesse. Os irmãos vendedores eram José Custódio Soares Barros e Luciano Soares de Morais; o terceiro irmão, que se tornaria proprietário da totalidade do escravo, era Joaquim Gomes Soares de Morais. Tendo em vista os preços médios calculados na localidade para escravos homens de 15 a 29 anos no intervalo 1870-1880 (Rs. 2:053\$763; Cf. MOTTA, 2012a, p. 230), o valor ajustado entre os irmãos pareceu-nos subestimado, mesmo considerando Francisco ter tão-somente 14 anos.

De modo consistente com a divisão em partes iguais do cativo pelos três contratantes, Joaquim recolheu meia sisa no valor de Rs. $20 \$ 000$, isto é, dois terços do valor do imposto então cobrado na venda de um escravo. Não localizamos José Custódio, Luciano ou Joaquim no Almanak de 1873, ainda que o tabelião tenha escrito serem todos residentes em Piracicaba. Por fim, os três estavam presentes ao ato e assinaram a escritura da compra e venda.

\section{Adão}

Também não localizados por nós no Almanak de 1873, embora presentes no Cartório e descritos pelo tabelião como moradores locais, foram os contratantes Theodoro Franco Bueno e Antonio Barbosa Pires. Em 02 de janeiro de 1874 foi lançada a escritura da venda que Theodoro fez a Antonio de parte do escravo Adão por Rs. 
500\$000. A meia sisa recolhida sobre a transação foi de Rs. $15 \$ 000$, indicando a comercialização de metade do cativo.

Das escrituras analisadas neste artigo, esta é a primeira a trazer, entre as informações sobre a mercadoria humana negociada, dados sobre a matrícula dos escravos realizada após a promulgação da Lei n. 2.040, de 28 de setembro de 1871, a Lei do Ventre Livre. Como observado em Motta (2012a, nota 4, p. 170):

\begin{abstract}
Por intermédio do Decreto $n^{\circ} 4.835$, de $1^{\circ}$ de dezembro de 1871 , D. Pedro II aprovou o regulamento para a matrícula especial dos escravos e dos filhos livres de mulher escrava. E, de fato, desde os últimos meses de 1872 os informes dessa matrícula passaram a ser descritos nas escrituras. Em Constituição, por exemplo, o primeiro registro a trazer tais informes era datado de 29 de outubro de 1872. Tratava-se da venda de Mathias por quinhentos mil-réis; os dados da matrícula desse senhor, de 60 anos de idade, são acrescidos mediante um "em tempo", após as assinaturas, evidenciando o esquecimento do tabelião, decerto ainda não acostumado com a nova exigência legal.
\end{abstract}

Adão, que era natural de Piracicaba, havia sido matriculado naquela localidade. Com 35 anos de idade, aquele escravo crioulo era solteiro, preto e do serviço da roça. O documento em questão, infelizmente, não trouxe quaisquer esclarecimentos sobre a forma de aquisição prévia da metade de Adão por Theodoro. Outrossim, não sabemos se o comprador era já proprietário da outra metade do cativo.

\title{
Catharina
}

Maior profusão de informações pode ser extraída das duas transações seguintes, ambas concernentes à venda de partes de uma mesma escrava, de nome Catharina. As respectivas escrituras foram datadas em 01 de abril e 22 de junho de 1874. No primeiro negócio, no valor de Rs. $900 \$ 000$, Joaquim Francisco de Barros, juntamente com dois irmãos seus, venderam as partes que possuíam na escrava, propriedade esta que haviam adquirido por herança de seu finado pai. O montante pago a título de meia sisa (Rs. 18\$000) indica terem sido então negociados três quintos de Catharina, cada um deles correspondente à parte da cativa que havia cabido a cada irmão.

Quem comprou em 01 de abril de 1874 os três quintos de Catharina foi Dona Ana Thereza de Barros, irmã dos vendedores, e ao tabelião foi dito que ela era já possuidora dos dois quintos restantes da escrava. Assim sendo, Ana também herdara um quinto de Catharina de seu pai. Porém, em que pese o declarado ao tabelião, apenas em junho daquele ano foi registrada no Cartório a transação do quinto restante. $E$ Ana o comprou, por Rs. $300 \$ 000$ (recolhendo de meia sisa Rs. 6\$000), de Lucas Antonio de Oliveira, que o havia obtido por herança de seu sogro. Vale dizer, Lucas era cunhado de Dona Ana Thereza.

Catharina era crioula, preta e solteira. Tinha 28 anos de idade e havia sido matriculada em Piracicaba. Seu valor era de Rs. 1:500\$000, inferido do preço das partes comercializadas. O preço nominal médio calculado com base em escrituras 
nas quais foram transacionadas 43 mulheres de 15 a 29 anos no período 1870-1880 igualou-se a Rs. 1:372\$814 (Cf. MOTTA, 2012a, p. 230). ${ }^{10}$

Todos os contratantes envolvidos nessas duas transações estiveram presentes no ato de registro das respectivas escrituras e assinaram o livro notarial pertinente. Entretanto, não teve sucesso nossa busca nominativa daquelas pessoas no Almanak de 1873.

\section{Anacleta}

Mais um negócio entre moradores em Piracicaba foi a venda de parte de Anacleta. Outra característica presente neste caso que vimos se repetir muitas vezes nessas pequenas transações envolvendo partes ideais de escravos foi o fato de vendedor e comprador serem irmãos. Conforme escreveu o tabelião na epígrafe do lançamento feito em 30 de julho de 1875:

Escritura de venda que faz Joaquim da Silva a seu irmão Paulo Luis da Silva da parte da escrava Anacleta que tinha direito por herança paterna em comum com o comprador, pela quantia de Rs. 500\$000. (Constituição-3)

A moça vendida tinha quinze anos de idade, era preta, solteira e natural de Piracicaba. Havia sido matriculada na Coletoria daquela mesma cidade. Paulo apresentou o comprovante do recolhimento, naquela data e na dita Coletoria, da importância de Rs. $15 \$ 000$ do imposto de meia sisa. Comprara assim o valor do imposto recolhido o indicou a metade de Anacleta herdada pelo irmão, e passara a desfrutar do domínio e posse da totalidade da cativa.

O preço total de Anacleta, portanto, seria de um conto de réis, menor do que o preço médio por nós referido no caso anterior. Há que ponderar é claro, que a idade dela igualou o limite inferior da faixa etária à qual se referiu o preço médio calculado, de 15 a 29 anos. No Almanak de 1873, Paulo Luiz da Silva é apontado como escrivão duas vezes nas informações sobre Piracicaba. A primeira, após o arrolamento do Subdelegado e de seus três suplentes; a segunda, após a lista dos quatro Juízes de Paz do município (Cf. LUNÉ; FONSECA, 1985, p. 463).

\section{Adão}

A venda da quinta parte do escravo Adão por Rs. 560\$000, registrada aos 02 de julho de 1877, trouxe duas novidades quando comparada aos demais negócios que vimos analisando. A primeira é que se tratou de uma transação realizada, em verdade, mais de dois anos antes do registro, porém até então restrita a um ajuste verbal entre as partes. Assim explicou o tabelião no documento:

(...) devendo os efeitos desta venda retratarem-se a seis de abril de mil oitocentos e setenta e cinco, época em que a venda foi efetuada verbalmente e o escravo entrou para a sociedade agrícola existente entre ele vendedor e o comprador. (Constituição-3) 
Quem vendeu o quinto de Adão foi Jayme Pinto de Almeida; o comprador, irmão de Jayme, foi Ricardo Pinto de Almeida. Se a demora no registro em Cartório foi ao que parece incomum, repetiu-se, não obstante, a venda de parte ideal de cativo entre irmãos, ambos presentes no ato do registro e moradores na cidade de Piracicaba.

A segunda novidade nessa transação tem a ver com Adão. Preto, casado e com 32 anos de idade, esse escravo era natural da província do Maranhão e havia sido matriculado no Corte do Rio de Janeiro. Posteriormente, foi averbado em Piracicaba. Isto é, ainda que o negócio entre os irmãos não tivesse ultrapassado o âmbito local, a pessoa comercializada havia vivenciado em algum momento anterior o comércio interprovincial de cativos, sendo trazido do Maranhão onde nascera para o Rio de Janeiro e daí levado para a província paulista. Estes os três lugares por onde sabemos passou a trajetória de Adão, mas pode muito bem ter sido mais variado o elenco de localidades em que ele esteve ao longo de sua vida em cativeiro. De qualquer modo, nenhuma referência é feita na escritura acerca do cônjuge daquele homem casado.

Adicionalmente, por ocasião do registro o imposto de meia sisa já havia sido objeto de nova alteração, elevando-se para Rs. 40\$000. Dessa forma, o comprador comprovou o recolhimento de um quinto desse valor, Rs. 8 \$000. O valor da escritura, Rs. $560 \$ 000$, sugere que o preço de Adão atingia quase três contos de réis (Rs. $2: 800 \$ 000)$, cifra que representa o pico atingido pelos preços nominais de escravos homens na fase mais intensa do comércio interno de escravos, na segunda metade dos anos de 1870 .

Em 1873, Jayme e Ricardo foram listados entre os capitalistas do município de Piracicaba. O primeiro, além disso, foi arrolado como Alferes Secretário do Estado Maior do $12^{\circ}$ Batalhão de Infantaria da Comarca da Constituição. E, entre as lojas de fazenda existentes naquele ano, uma era denominada Jayme Pinto de Almeida \& Comp. (Cf. LUNÉ; FONSECA, 1985, p. 462-465).

\section{Eva}

Na penúltima transação objeto de nossa atenção neste artigo, datada aos 15 de março de 1881, defrontamo-nos com uma operação em que a venda de parte de uma escrava é realizada de modo concomitante à doação de outra parte da mesma cativa. A vendedora e doadora foi Dona Leopoldina Joaquina de Barros Cunha; o comprador e donatário foi o filho de Leopoldina, Claudino de Almeida Cunha. Mãe e filho fizeram-se presentes e assinaram o documento, sendo ambos descritos como moradores em Piracicaba.

Eva era uma viúva de 48 anos de idade, preta e cozinheira, natural da província de São Paulo e matriculada na Coletoria de Piracicaba. A escrava, "filha legítima dos finados escravos Felipe e Mariana”, compôs a meação de Dona Leopoldina no inventário de seu marido, Capitão José Wenceslau de Almeida Cunha, tendo sido avaliada por novecentos mil réis, mesmo valor atribuído à escritura. No Almanak de 1873 foi ainda o Capitão quem localizamos, tanto entre os capitalistas como entre os proprietários listados no município da Piracicaba. 
A viúva escravista fez doação da parte de Eva correspondente a Rs. $400 \$ 000$ "por conta da futura legítima" de Claudino,

na qual [legítima-JFM/LSL] deverá ser em tempo descontada, e faz venda de outra parte da escrava, no valor de quinhentos mil-réis, que ao fazer desta recebeu parte em um vale firmado por seu filho (...) e parte em dinheiro, dando quitação ao comprador. (Piracicaba-5)

Essa proporção descrita entre parte doada e parte vendida não encontrou correspondência perfeita no recolhimento da meia sisa. De fato, foi pago de tributo a importância de Rs. $20 \$ 000$, isto é, a exata metade do imposto devido na venda de um escravo.

\section{Honória}

O último dos pequenos negócios envolvendo partes ideais de escravos registrado em Piracicaba foi datado em 12 de outubro de 1885. José Rodrigues Ayrão vendeu para Antonio Gonçalves Ribeiro a terça parte de Honória, preta, solteira, de 28 anos de idade, descrita como "filha natural de Maria, capaz para qualquer serviço" e matriculada naquela cidade. Os dois contratantes assinaram a escritura de venda; o vendedor era residente no município de Piracicaba e o comprador no município de São Pedro, naquele mesmo Termo. Gonçalves Ribeiro, ademais, comprovou o recolhimento do imposto de meia sisa no valor de Rs. $16 \$ 000$. Àquela data, o tributo devido correspondia a Rs. $48 \$ 000$ por escravo vendido sendo, portanto, compatíveis a quantia paga à Coletoria e a proporção negociada da cativa.

Informou ainda o vendedor que a matrícula de Honória, em 31 de agosto de 1872, quando a escrava tinha 16 anos, fora feita por sua sogra, Maria Ferreira das Dores,

(...) cuja escrava ele possui em sociedade com o atual comprador, que comprou já outras duas partes de seus cunhados, genros da matriculante também. (Piracicaba-6)

No Almanak de 1873, Antonio Gonçalves Ribeiro foi listado entre os fazendeiros de açúcar existentes na Freguesia de São Pedro, então pertencente ao município de Santa Bárbara. Era proprietário da Fazenda Araraquamirim (Cf. LUNÉ; FONSECA, 1985, p. 469).

\section{Considerações finais}

Analisamos neste artigo 17 transações de compra e venda de partes ideais de escravos. Em nove desses negócios, as pessoas comercializadas eram homens com idades entre 14 e 35 anos. As mulheres vendidas em partes foram seis, e suas idades oscilaram entre 13 e 48 anos; dois desses casos geraram duas escrituras. Além disso, duas escravas foram transacionadas juntamente com suas filhas, bebês que não haviam ainda completado um ano de vida. Em todas as demais situações acompanhadas, uma única pessoa foi objeto da transação. 
Esses pequenos negócios foram todos registrados no período de 1861 a 1887, etapa derradeira de vigência da escravidão no Brasil, instituição que seria extinta em maio do ano seguinte ao limite superior do intervalo contemplado. Pequenos negócios, ademais, ocorridos em uma localidade, Piracicaba, situada no oeste histórico de São Paulo e que vivenciou, ao longo daqueles 27 anos, o intenso movimento de expansão da lavoura cafeeira na província paulista.

Essas compras e vendas de partes ideais de pessoas escravizadas corresponderam a cerca de $3 \%$ dos negócios envolvendo a mercadoria humana registrados no $2^{\circ}$ Cartório de Notas de Piracicaba. E os 17 cativos transacionados "em partes" perfizeram aproximadamente um centésimo do total de escravos objeto daqueles registros.

Valemo-nos de processos de inventários post-mortem datados de 1849 a 1888 e referentes a outra localidade paulista (Ribeirão Preto) com o intuito de construir um referencial comparativo que contemplasse o "estoque" de escravos, em vez do "fluxo" aferido pelas escrituras. Verificamos que, tanto no fluxo como no estoque, a posse parcial de pessoas correspondia a uma pequena parcela do conjunto da escravaria. Contudo, os maiores porcentuais foram os calculados nos inventários. É plausível sugerirmos que escravistas possuidores de frações ideais de escravos não detivessem meios e/ou vontade de adquirir o restante e/ou desfazer-se da parte possuída daquelas pessoas. Assim, a maior incidência, nos inventários versus nas escrituras, dessas pessoas partidas poderia ser um indício de que a mera propriedade da mercadoria humana eventualmente gerasse um interesse que ia além do efetivo usufruto (ou pelo menos do pleno usufruto) da mão de obra compulsória.

De outra parte, é igualmente cabível sugerirmos que a leitura das descrições de transações de partes de escravos, por nós efetuada na seção anterior deste artigo, tenha corroborado e mesmo reforçado o entendimento prévio de muitos leitores acerca dos horrores da escravidão. Afinal, a possibilidade de ser vendido, trocado, doado, etc., e todo o conjunto de prováveis, ou pelo menos possíveis, decorrências deletérias de tais eventos, decerto parecerá a muitos ainda mais terrível quando vendas, trocas e doações estiveram referidas a metade, um terço, dois quintos etc. dos cativos. Poderíamos talvez afirmar que é como se esses negócios envolvendo partes ideais acentuassem o atributo de coisas possuído por aquelas pessoas.

Não obstante, talvez não seja esse o único entendimento possível para essas situações por nós estudadas. É certo que a morte de escravistas, seguida da partilha de seus patrimônios (do qual, é claro, faziam parte os escravos), e a decisão tomada por proprietários de transacionarem sua propriedade humana foram dois momentos dos mais críticos, ambos com elevado potencial destruidor no tocante à vida dos cativos porventura obrigados a vivenciá-los. Contudo, a própria ligação identificada praticamente em todos os casos entre a partilha de bens inventariados e a realização de negócios envolvendo partes de escravos pode, de forma também bastante plausível, ser entendida como um traço característico que acentua a natureza quase meramente contábil daqueles negócios. Até a definição dos preços ajustados nesse tipo de transação, como vimos, parecia muitas vezes em alguma medida descolada 
dos preços médios praticados nas operações de compra e venda características do comércio de escravos.

Dito de outro modo, transacionar "um pedaço" de uma pessoa, o mais das vezes, equivalia a tão-somente ajustar a matemática cega da divisão equânime de um patrimônio entre aqueles que o herdavam. ${ }^{11}$ Este propósito ficou claramente evidenciado pela frequência das transações entre herdeiros compondo o conjunto por nós analisado, envolvendo irmãos, cunhados, genros, pais e filhos. ${ }^{12}$

\section{Referências}

CONRAD, Robert Edgar. Tumbeiros: o tráfico escravista para o Brasil. São Paulo: Brasiliense, 1985.

FRAGOSO, João Luis Ribeiro; FLORENTINO, Manolo Garcia. Marcelino, filho de Inocência Crioula, neto de Joana Cabinda: um estudo sobre famílias escravas em Paraíba do Sul (1835-1872). Estudos Econômicos, v. 17, n. 2, p. 151-173, 1987.

LOBATO, Monteiro. A onda verde. São Paulo: Editora Globo, 2009.

LOPES, Luciana Suarez. Sob os olhos de São Sebastião: a cafeicultura e as mutações da riqueza em Ribeirão Preto, 1849-1900. Tese (Doutorado em História) - Faculdade de Filosofia, Letras e Ciências Humanas, Universidade de São Paulo. São Paulo, 2005.

MILLIET, Sergio. Roteiro do café e outros ensaios: contribuição para o estudo de história econômica e social do Brasil. São Paulo: Departamento de Cultura, 1939.

MOTTA, José Flávio. Escravos daqui, dali e de mais além: o tráfico interno de cativos em Constituição (Piracicaba), 1861-1880. Revista Brasileira de História, v. 26, n. 52, p. 15-47, 2006.

MOTTA, José Flávio. Derradeiras transações: o comércio de escravos nos anos de 1880 (Areias, Piracicaba e Casa Branca, Província de São Paulo). Almanack Braziliense, n. 10, p. 147-163, 2009.

MOTTA, José Flávio. O tráfico de escravos velhos (Província de São Paulo, 1861-1887). História. Questões \& Debates, n. 52, p. 37-69, 2010.

MOTTA, José Flávio. Escravos daqui, dali e de mais além: o tráfico interno de cativos na expansão cafeeira paulista (Areias, Guaratinguetá, Constituição/ Piracicaba e Casa Branca, 1861-1887). São Paulo: Alameda/FAPESP, 2012a.

MOTTA, José Flávio. A lei, ora a lei! Driblando a legislação no tráfico interno de escravos no Brasil (1861-1887). História e Economia - Revista Interdisciplinar, v. 10, n. 1, p. 15-28, 2012b.

MOTTA, José Flávio. Vendas condicionais de escravos (Casa Branca, província de São Paulo, anos de 1870). História e Economia - Revista Interdisciplinar, v. 12, n. 1, p. 61-84, 2014. 
MOTTA, José Flávio. Crianças no apogeu do tráfico interno de escravos (Piracicaba, Província de São Paulo, 1874-1880). História Econômica \& História de Empresas, v. 18, n. 2, p. 291-322, 2015.

MOTTA, José Flávio; MARCONDES, Renato Leite. O comércio de escravos no Vale do Paraíba paulista: Guaratinguetá e Silveiras na década de 1870. Estudos Econômicos, v. 30, n. 2, p. 267-299, 2000.

MOTTA, José Flávio; VALENTIN, Agnaldo. A estabilidade das famílias em um plantel de escravos de Apiaí (SP). Afro-Ásia, n. 27, p. 161-192, 2002.

SLENES, Robert Wayne. The demography and economics of brazilian slavery: 18501888. Tese (Doutorado em História) - Stanford University. Stanford, 1976.

TESSITORE, Viviane. As fontes da riqueza pública: tributos e administração tributária na Província de São Paulo (1832-1892). Dissertação (Mestrado em História Social) Faculdade de Filosofia, Letras e Ciências Humanas, Universidade de São Paulo. São Paulo, 1995.

\section{Fontes primárias manuscritas}

Livros especiais para transações envolvendo escravos (datas dos termos de abertura): CONSTITUIÇÃO-1 - Termo de abertura em 28 de junho de 1861; CONSTITUIÇÃO-2 Termo de abertura em 28 de outubro de 1866; CONSTITUIÇÃO-3 - Termo de abertura em 14 de dezembro de 1874; PIRACICABA-4 - Termo de abertura em 22 de maio de 1878; PIRACICABA-5 - Termo de abertura em 20 de outubro de 1879; PIRACICABA-6 [Do sexto livro coletado para Piracicaba não localizamos a primeira folha, com o termo de abertura]; PIRACICABA-7 - Termo de abertura em 8 de agosto de 1885.

Processos de Inventário Post-Mortem: Primeiro e Segundo Ofícios de Ribeirão Preto, de 1856 a 1888; Primeiro e Segundo Ofícios de São Simão, de 1849 a 1888.

\section{Fontes primárias impressas}

Coleção de Leis do Império do Brasil, 1808-1889. Disponível em: <http://www2.camara. gov.br/legislacao/publicacoes/doimperio>. Acesso em 19 de janeiro de 2018.

LUNÉ, Antonio José Baptista de; FONSECA, Paulo Delfino da (Orgs.). Almanak da província de São Paulo para 1873. Ed. facsimilada. São Paulo: Imprensa Oficial do Estado-IMESP, Arquivo do Estado de São Paulo, 1985.

MARQUES, Manuel Eufrásio de Azevedo. Apontamentos históricos, geográficos, biográficos, estatísticos e noticiosos da Província de São Paulo, seguidos da cronologia dos acontecimentos mais notáveis desde a fundação da Capitania de São Vicente até o ano de 1876. São Paulo: Comissão do IV Centenário da Cidade de São Paulo, 1953, 2v.

ZALUAR, Augusto Emílio. Peregrinação pela província de São Paulo (1860-1861). Belo Horizonte: Itatiaia ; São Paulo: EDUSP, 1975. 


\section{Notas}

1 De fato, o nome de Constituição foi atribuído à localidade em 1822, quando elevada à categoria de vila, e substituiu o nome anterior da até então Freguesia de Santo Antônio de Piracicaba, criada em 1769 (Cf. LUNÉ; FONSECA, 1985, p. 462). Por conveniência nossa e dos leitores referirnos-emos sempre a Piracicaba neste texto, mesmo quando estivermos analisando, em verdade, documentos que fazem menção a Constituição.

2 "O objeto precípuo desse decreto era regular a arrecadação do imposto da meia sisa devido nesses negócios” (MOTTA, 2012a, nota 25, p. 78).

3 Uma análise mais aprofundada do conjunto desses documentos, contemplando também a comparação com outros conjuntos concernentes a outras localidades paulistas, está em Motta (2012a). E estudos de vários outros tópicos mais específicos, baseado nesse mesmo banco de dados, estão disponíveis em Motta (2006, 2009, 2010, 2012b, 2014 e 2015).

${ }^{4}$ Houve também casos de doação e de troca de partes de cativos, assim como algumas vendas de partes de um número mais elevado de escravos; porém, conforme declaramos já ao início do texto, optamos por nos restringir, neste artigo, aos pequenos negócios de compra e venda.

5 Não se pode descartar, ademais, que essa "resolução" pudesse eventualmente abrir espaços de negociação nos quais se fizesse presente a agência escrava. Tal possibilidade, embora conformando uma hipótese instigante e mesmo sedutora, não pode ser inferida da documentação por nós utilizada neste artigo.

${ }^{6}$ Essa documentação foi objeto do estudo realizado por Lopes (2005).

7 Para a comodidade dos leitores, optamos por atualizar a grafia das palavras nas citações extraídas das fontes primárias manuscritas, ao passo que mantivemos a pontuação original.

${ }^{8}$ As alterações havidas na cobrança desse imposto ao longo do período sob análise, evidenciadas pelo manuseio da documentação, estão igualmente indicadas, por exemplo, nos trabalhos de Slenes (1976, nota 25, p. 164-165) e Tessitore (1995, p. 245-250).

9 Um homônimo do funileiro de Santa Bárbara era o Tenente Coronel Comandante José Ferraz de Campos, do Estado Maior do $12^{\circ}$ Batalhão de Infantaria da Guarda Nacional, na Comarca da Constituição (Cf. LUNÉ; FONSECA, 1985, p. 461-462). Cremos que este não seria o "nosso" Ferraz de Campos, pois se o fosse alguma menção à sua patente decerto teria sido feita pelo tabelião no documento que compulsamos. Tal menção fez-se presente, por exemplo, quando outro Tenente Coronel, José Ferraz de Camargo, atuou como comprador de Silvério, caso descrito a seguir.

10 Convém lembrarmos que a libertação do ventre da escrava foi forte condicionante de um movimento de desvalorização das cativas no decurso dos anos de 1870. Tomados os preços reais das mulheres de 15 a 29 anos de idade, Motta (2012a, p. 231) observou: "seus preços médios em 1870-73 eram 10,9\% menores do que em 1861-69; e, em 1874-80, eram 15,4\% menores do que em 1870-73".

${ }^{11 E ́ ~ p r e c i s o ~ s a l i e n t a r m o s ~ q u e ~ e s s e, ~ d i g a m o s ~ a s s i m, ~ m e r o ~ a j u s t e ~ c o n t a ́ b i l ~ n a ̃ o ~ i m p l i c o u ~ s e m p r e ~}$ necessariamente a transação de partes ideais de escravos. O que de resto é evidente. Em outras palavras, mesmo partilhas envolvendo cativos "inteiros" ou grupos de pessoas poderiam muito bem representar meros ajustes contábeis.

12 Vale aqui indicar, reiterando o comentário expresso na nota 5, o seguinte: muito embora não se possa negar que esses ajustes obedecessem, sobretudo, os interesses de máxima exploração dos escravos, é também possível sugerir que eles abrissem espaço, ao mesmo tempo, para a ação e o atendimento, ao menos em alguma medida, dos interesses das próprias pessoas negociadas, algo possível exatamente porque eram pessoas, não apenas coisas ou bens semoventes como o gado. As fontes documentais por nós utilizadas neste artigo não nos permitem, entretanto, corroborar esta última sugestão. 


\section{Nota do Editor}

A revista História (São Paulo) agradece à FAPESP pelo apoio financeiro, na modalidade Auxílio à Pesquisa - Publicações/Periódicos (Processo n. 2020/04324-9), para a publicação deste artigo.

José Flávio MOTTA é bacharel em Ciências Econômicas pela Universidade de São Paulo (USP, 1982), doutor em Economia pelo Instituto de Pesquisas Econômicas da FEA/USP (1990) e livredocente do Departamento de Economia da FEA/USP (2010). Atualmente é Professor Titular desse mesmo Departamento. Leciona e orienta no Programa de Pós-Graduação em História Econômica da FFLCH/USP e no Programa de Pós-Graduação em Economia da FEA/USP. Desenvolve suas pesquisas na área de História Econômica, em especial sobre o tema da economia e demografia da escravidão no Brasil. Além de vários artigos e capítulos de livros, é autor dos livros Corpos escravos, vontades livres: posse de cativos e familia escrava em Bananal (1801-1829) (São Paulo: Annablume/FAPESP, 1999) e Escravos Daqui, Dali e de Mais Além: o tráfico interno de cativos na expansão cafeeira paulista (Areias, Guaratinguetá, Constituição/Piracicaba e Casa Branca, 1861-1887) (São Paulo: Alameda/FAPESP, 2012).

Luciana Suarez GALVÃo possui graduação em Economia pela Universidade de São Paulo (1997), Mestrado em Economia pela Universidade Estadual Paulista Júlio de Mesquita Filho (2000), Doutorado em História Econômica pela Universidade de São Paulo (2005), e livre-docência em Formação Econômica e Social do Brasil pela Faculdade de Economia, Administração e Contabilidade da Universidade de São Paulo (2019). Atualmente é professora do Instituto de Estudos Brasileiros e do Programa de Pós-Graduação em História Econômica da Faculdade de Filosofia, Letras e Ciências Humanas, ambos da Universidade de São Paulo. Tem experiência em pesquisas na área de História Econômica, atuando principalmente nos seguintes temas: finanças públicas, alocação e acumulação de riqueza e estrutura da posse de escravos. 